\title{
COPD management costs according to the frequency of COPD exacerbations in UK primary care
}

This article was published in the following Dove Press journal:

International Journal of COPD

9 January 2014

Number of times this article has been viewed

\author{
Yogesh Suresh Punekar' \\ Amit Shukla ${ }^{2}$ \\ Hana Müllerova ${ }^{3}$ \\ 'Global Health Outcomes, \\ GlaxoSmithKline R\&D, Uxbridge, \\ UK; ${ }^{2}$ Worldwide Epidemiology, \\ GlaxoSmithKline R\&D, Upper \\ Providence, PA, USA; ${ }^{3}$ Worldwide \\ Epidemiology, GlaxoSmithKline R\&D, \\ Uxbridge, UK
}

Background: The economic burden of chronic obstructive pulmonary disease (COPD) exacerbations is significant, but the impact of other sources on the overall cost of COPD management is largely unknown. We aimed to estimate overall costs for patients experiencing none, one, or two or more exacerbations per year in the UK.

Methods: A retrospective cohort of prevalent COPD patients was identified in the Clinical Practice Research Datalink UK database. Patients with information recorded for at least 12 months before and after cohort entry date were included (first prevalent COPD diagnosis confirmed by spirometry on/after April 1, 2009). Patients were categorized as having none, one, or two or more moderate-to-severe COPD exacerbations in the 12 months after cohort entry and further classified by the Global initiative for chronic Obstructive Lung Disease (GOLD) category of airflow obstruction and the Medical Research Council dyspnea scale. Study outcomes included counts of general practitioner interactions, moderate-severe COPD exacerbations, and non-COPD hospitalizations. Estimated resource use costs were calculated using National Health Service reference costs for 2010-2011.

Results: The cohort comprised 58,589 patients (mean age 69.5 years, mean dyspnea grade 2.5, females $46.6 \%$, current smokers $33.1 \%$ ). The average total annual per patient cost of COPD management, excluding medications, was $£ 2,108$ for all patients and $£ 1,523, £ 2,405$, and $£ 3,396$ for patients experiencing no, one, or two or more moderate-to-severe exacerbations, respectively. General practitioner interactions contributed most to these annual costs, accounting for $£ 1,062$ (69.7\%), £1,313 (54.6\%), and £1,592 (46.9\%) in patients with no, one, or two or more moderateto-severe exacerbations, respectively.

Conclusion: Disease management strategies focused on reducing costs in primary care may help reduce total COPD costs significantly.

Keywords: chronic obstructive pulmonary disease, frequent exacerbations, infrequent exacerbations, health resources, health care costs

\section{Introduction}

Chronic obstructive pulmonary disease (COPD) is a highly prevalent ${ }^{1}$ and debilitating disease that has a significant impact on patient quality of life and the costs borne by the health care system. ${ }^{2,3}$ An exacerbation of COPD is the most common condition that requires hospital admission, ${ }^{4}$ and contributes substantially to the related economic impact. ${ }^{5-7}$ Therefore, COPD exacerbations have been considered the most important target for reducing costs. A study in the UK National Health Service (NHS) in 2001 showed that the total excess primary care cost associated with acute exacerbations of chronic bronchitis in the COPD-diagnosed population was $£ 35.7$ million. This included the excess cost of all prescription medications, general practitioner (GP)
Correspondence: Yogesh Suresh Punekar Global Health Outcomes,

GlaxoSmithKline, Stockley Park,

Uxbridge UBI I IBT, UK

Tel +440208990 4786

Fax +4402089903505

Email yogesh.q.punekar@gsk.com
International Journal of COPD 2014:9 65-73

Dovepress

http://dx.doi.org/10.2147/COPD.S544I7 (c) (i) (5) 2014 Punekar et al. This work is published by Dove Medical Press Limited, and licensed under Creative Commons Attribution - Non Commercial (unported, v3.0) License. The full terms of the License are available at http://creativecommons.org/licenses/by-nc/3.0/. Non-commercial uses of the work are permitted without any further permisson for medical Press Limited, provided the work is properly attributed. Permissions beyond the scope of the License are administered by Dove Medical Press Limited. Information on how to request permission may be found at: http://www.dovepress.com/permissions.php 
consultations, hospital emergency room visits, and inpatient hospital episodes. ${ }^{8}$ Similarly, a retrospective analysis of data from a large national health plan database in the US showed that COPD-related mean annual costs were 56\% higher for patients with two or more exacerbations compared with the overall population of COPD patients. ${ }^{8}$ This finding has also been reflected in other studies conducted across Europe and the US, suggesting that prevention of exacerbations requiring hospitalization is the foremost factor critical in the development of a cost-effective disease management strategy. ${ }^{5-7,10,11}$

In contrast, symptomatic patients who are at a low risk of exacerbation represent an unexplored population with respect to health care costs. These patients continue to report symptoms, potentially consuming significant primary care resources. Therefore, it is important to assess the severity of these symptoms and their impact on health care resource utilization. The annual administration of the Medical Research Council (MRC) dyspnea scale in the UK primary care setting instituted by the UK NHS Quality Outcomes Framework (since April 2009) allows such quantitative assessment of symptoms of dyspnea. ${ }^{12}$ A previous study using this dyspnea recording has found a high prevalence of dyspnea in the primary care COPD population in the UK. ${ }^{13}$

This study evaluated the primary care COPD population and its costs using the Clinical Practice Research Datalink (CPRD) database. The study objectives were to estimate resource use and the associated costs among patients classified by no, one, and two or more exacerbations and to compare resource use and costs between different levels of exacerbations across the Global initiative for chronic Obstructive Lung Disease (GOLD) stages of airflow obstruction and MRC dyspnea categories.

\section{Materials and methods Study design}

This was a retrospective cohort study of COPD patients identified from primary care in the UK using the CPRD. CPRD is the NHS observational data and interventional research service, jointly funded by the NHS National Institute for Health Research and the Medicines and Healthcare products Regulatory Agency. ${ }^{14}$ In this study, we used the primary care electronic medical records database part of the CPRD, formerly known as the General Practice Research Database. ${ }^{14}$ About 660 general practices participate in the CPRD; the database contains data for about 11 million patients, mostly from England and Wales. The COPD cohort study design and analysis methods (protocol WEUSKOP5903), prior to the cost estimation and modeling described herein, were approved by the CPRD Independent Scientific Advisory Committee.

Patients aged 40 years or older with one or more records for diagnosis of COPD (Table S1) on or after April 1, 2009 were included. Date of the first recorded COPD diagnosis on or after April 1, 2009 was taken as the cohort entry date. Patients were required to have at least a 12 month history before and after cohort entry and a record of forced expiratory volume in one second/forced vital capacity $\left(\mathrm{FEV}_{1} / \mathrm{FVC}\right)<0.7$. The observation period consisted of a fixed period of 12 months of follow-up after cohort entry. The corresponding 12 month data prior to cohort entry have been referred to as the pre-observation period. Health care resource use during the observation and pre-observation periods was captured as moderate-to-severe exacerbations, GP interactions, and non-COPD hospitalizations. Exacerbations were further split into moderate and severe events. A moderate exacerbation was defined as an episode characterized by management with antibiotics commonly used in COPD exacerbations and oral corticosteroids (within 5 days of initiation of antibiotics), and/or a medical diagnosis of COPD exacerbation. A severe exacerbation was defined as an episode characterized by hospitalization for COPD. These were selected using an algorithm that identified hospital admissions of specific COPD cause or general admissions with a record of COPD diagnosis or medication up to 3 days before and 7 days after the index hospitalization date. The first event qualifying as an exacerbation was considered as the start date of the episode. Thereafter, a 14 day moving window ${ }^{15}$ was applied to identify at least 2 weeks of an exacerbation event-free period to ensure that a relapse was not considered a separate exacerbation. GP interactions were recorded and classified as administrative contact, surgery correspondence, visit to a surgery nurse, in-person surgery visit, out-of-office GP visit, or a GP home visit. Non-COPD hospitalizations were defined as hospital admission for specific non-COPD cause or general hospital admissions (without a specific cause) with no record of COPD diagnosis or medication recorded around this event.

Patients were classified by their moderate-to-severe exacerbation frequency (no, one, or two or more) during the observation period. Further, exacerbation frequency and medications in the pre-observation period and comorbidities at baseline were recorded. All costs were calculated using 2011 prices (except the medication costs, which were taken from 2012) expressed as mean annual costs per patient, and summarized (Table 1). For patients with no, one, and two or more exacerbations, baseline characteristics and costs estimated during the observation period were 
Table I Unit costs estimated for the resource use categories

\begin{tabular}{|c|c|c|}
\hline Resource use item & Unit cost & Reference \\
\hline Moderate exacerbation & $£ 85.29$ & $\begin{array}{l}\text { NHS reference costs } \\
2010-2011\end{array}$ \\
\hline Severe exacerbation & $£ \mathrm{fl}, 263.76$ & $\begin{array}{l}\text { NHS reference costs } \\
2010-2011\end{array}$ \\
\hline Hospital episode & $€ 1,366.88$ & PSSRU 2011 \\
\hline GP practice in-person visit & $£ 36$ & PSSRU 20I I, Page I49 \\
\hline GP practice nurse visit & $€ 13$ & $\begin{array}{l}\text { (Based on I5.5-minute } \\
\text { consultation) } \times \notin 5 \text { I per } \\
\text { hour of face to face contact }\end{array}$ \\
\hline GP home visit & $f|2|$ & PSSRU 20II, Page 149 \\
\hline GP out-of-office visit & $f|2|$ & $\begin{array}{l}\text { Assumed to be the same } \\
\text { as home visits }\end{array}$ \\
\hline $\begin{array}{l}\text { GP practice administrative } \\
\text { contact }\end{array}$ & $£ 22$ & $\begin{array}{l}\text { PSSRU 20I I, Page I49; } \\
\text { considered equivalent to } \\
\text { telephone consultation }\end{array}$ \\
\hline $\begin{array}{l}\text { GP practice } \\
\text { correspondence }\end{array}$ & $£ 3$ & $\begin{array}{l}\text { Based on } 30 \% \text { of indirect } \\
\text { contact of } 15.5 \text {-minute } \\
\text { consultation }(0.3 \times 15.5) \times \\
£ 39 \text { per hour of non-face } \\
\text { to face contact }\end{array}$ \\
\hline
\end{tabular}

Abbreviations: GP, general practitioner; NHS, National Health Service; PSSRU, Personal Social Services Research Unit.

compared using the chi-square test and one-way analysis of variance.

Bivariate relationships with exacerbation frequency categories were evaluated using the Cochran-Mantel-Haenszel test (for categorical or ordinal variables), polyserial correlations (for continuous variables), or negative binomial modeling with exacerbation frequency during the observation period as the predictor variable while controlling for age and gender to assess a relationship with the count data.

The cost of a severe exacerbation was estimated using the relevant COPD-related Healthcare Resource Groups (HRG) codes (DZ21A-K for short stay and long stay) further weighted by the reported annual number of episodes from the NHS reference costs. ${ }^{16}$ In addition, it was assumed that $67 \%$ of patients would arrive at the hospital by ambulance, based on a clinical audit of COPD exacerbations in $2008 .{ }^{17}$ Therefore, $67 \%$ of the HRG cost for ambulance transportation (code PS06B) was added to the weighted COPD HRG costs. Costs of a moderate exacerbation were compiled based on the resource use stated in the report by the GOLD Strategy Group $^{18}$ and combined with cost data from the NHS reference costs, ${ }^{16}$ the Personal Social Services Research Unit (PSSRU) $2011,{ }^{19}$ and the British National Formulary $65 .{ }^{20}$ This included a GP consultation lasting 11.7 minutes, an accident and emergency visit with no admission (in 29\% of cases), and a prescription of prednisolone $(30 \mathrm{mg}$ ) and co-amoxiclav $(500 \mathrm{mg}){ }^{21}$ The cost of a non-COPD hospitalization was estimated as a weighted average of short-stay and long-stay hospital episodes from PSSRU costs. ${ }^{19}$

The costs of a GP visit in surgery and a GP visit at home were estimated to be $£ 36$ and $£ 121$, respectively, based on PSSRU costs. ${ }^{19}$ The cost of an out-of-office GP visit was assumed to be equivalent to a GP home visit, and the cost of a GP administrative contact (£22) was assumed to be equivalent to a phone consultation at a GP surgery. The cost of a nurse visit at a GP practice was estimated to be $£ 13$ based on a typical 15.5-minute face to face consultation, and the cost of a GP correspondence was estimated to be $£ 3$ based on $30 \%$ indirect costs of a typical non-face to face consultation. ${ }^{19}$

These unit costs were then applied to the corresponding annual resource use counts to calculate the total annual COPD management costs for the entire cohort and for patients with no, one, and two or more exacerbations. Costs estimated during the observation period were further summarized by the GOLD stage of airflow obstruction ${ }^{22}$ and the level of dyspnea estimated using the MRC dyspnea scale ${ }^{23}$ captured nearest to the cohort entry.

\section{Results}

\section{Patient disposition and demographic characteristics}

The final analytic COPD cohort consisted of 58,589 patients (Figure S1) with a mean follow-up of 13.5 years in CPRD. The cohort had a mean age of 69.5 years; $46.6 \%$ of the patients were female and $33.1 \%$ were current smokers (Table 2). The mean ( \pm standard deviation) $\mathrm{FEV}_{1}$ percent predicted value at baseline was $60.0 \pm 20.5$, with a majority of patients in the GOLD 2 category. The mean MRC grade at baseline was $2.5 \pm 1.0$.

The cohort consisted of 31,049 (52.9\%), 14,189 (24.2\%), and 13,351 (22.7\%) patients experiencing no, one, and two or more episodes of exacerbation during the observation period, respectively (Table 2). Patients with a higher exacerbation frequency had lower percent predicted $\mathrm{FEV}_{1}(P<0.0001)$, more dyspnea $(P<0.0001)$, and a higher comorbidity index $(P<0.0001)$ at or near baseline. The resources collected in the pre-observation and observation periods for each of the three groups are presented in Table 3.

\section{Cost of COPD treatment}

The mean total annual COPD management cost per patient was $£ 2,108$ in the observation period. Of these costs, $£ 257$ was accounted for by exacerbations, £637 was from non-COPD hospitalizations, and £1,213 was due to GP interactions. The corresponding total COPD management 
Table 2 Patient disposition and demographic characteristics at the start of the observation period, split by frequency of moderate-tosevere exacerbations during observation period

\begin{tabular}{lllll}
\hline Patient variable & $\begin{array}{l}\text { Moderate-severe } \\
\text { exacerbations: none }\end{array}$ & $\begin{array}{l}\text { Moderate-severe } \\
\text { exacerbations: one }\end{array}$ & $\begin{array}{l}\text { Moderate-severe } \\
\text { exacerbations: } \\
\text { two or more }\end{array}$ & $\begin{array}{l}\text { P-value across } \\
\text { exacerbation } \\
\text { categories }\end{array}$ \\
\hline${ }^{a}$ All COPD, n & 31,049 & 14,189 & $13,35 I$ & $<0.0001$ \\
Female, n (\%) & $13,619(43.86)$ & $6,831(48.14)$ & $6,832(51.17)$ & 0.0180 \\
Age, mean (SD) & $69.3(10.46)$ & $69.77(10.32)$ & $69.44(10.17)$ & $<0.0001$ \\
Current smokers, n (\%) & $10,531(33.92)$ & $4,667(32.89)$ & $4,173(31.26)$ & 0.0431 \\
BMI, mean (SD) & $26.98(5.72)$ & $27.04(5.95)$ & $26.82(6.04)$ & $<0.0001$ \\
FEV, \%pred, mean (SD) & $62.83(19.94)$ & $59.39(20.05)$ & $54.15(20.74)$ & $<0.0001$ \\
MRC grade, mean (SD) & $2.28(0.99)$ & $2.51(1.03)$ & $2.83(1.08)$ & $<0.0001$ \\
Charlson score, mean (SD) & $2.48(1.63)$ & $2.56(1.66)$ & $2.58(1.66)$ & \\
\hline Not
\end{tabular}

Note: ${ }^{a}$ Number of patients experiencing no, one, and two or more moderate-to-severe exacerbations during the 12 month observation period.

Abbreviations: \%pred, percent predicted; BMI, body mass index; COPD, chronic obstructive pulmonary disease; FEV , forced expiratory volume at one second; MRC, Medical Research Council dyspnea scale; SD, standard deviation.

cost in the pre-observation period was $£ 1,826$, comprising $£ 200$ due to exacerbations, $£ 572$ due to non-COPD hospitalizations, and $£ 1,054$ due to GP interactions.

When split by the frequency of moderate-to-severe exacerbations during the observation period, the total annual per patient COPD costs were $£ 1,523, £ 2,405$, and $£ 3,396$ for patients with no, one, and two or more exacerbations, respectively. GP interactions contributed most to these annual costs, accounting for $£ 1,062(69.7 \%)$ in patients with no exacerbations, $£ 1,313(54.6 \%)$ in patients with one exacerbation, and $£ 1,592$ (46.9\%) in patients with two or more exacerbations (Figure 1). For this cohort, the pre-observation mean

Table 3 Health care utilization during the 12 month observation period before and after cohort entry

\begin{tabular}{|c|c|c|c|c|}
\hline Patient variable & $\begin{array}{l}\text { Moderate-severe } \\
\text { exacerbations: none } \\
n=31,049\end{array}$ & $\begin{array}{l}\text { Moderate-severe } \\
\text { exacerbations: one } \\
n=14,189\end{array}$ & $\begin{array}{l}\text { Moderate-severe } \\
\text { exacerbations: } \\
\text { two or more } \\
n=|3,35|\end{array}$ & $\begin{array}{l}P \text {-value across } \\
\text { the exacerbation } \\
\text { categories }^{\#}\end{array}$ \\
\hline \multicolumn{5}{|c|}{ Resource category 12 months prior to start of observation period, $\mathrm{n}(\mathrm{rate})^{\mathrm{a}}$} \\
\hline Moderate exacerbations & $9,226(0.30)$ & $8,804(0.62)$ & $19,523(1.46)$ & $<0.0001 /<0.0001$ \\
\hline Severe exacerbations & $2,278(0.07)$ & $1,753(0.12)$ & $2,709(0.20)$ & $0.2065 /<0.0001$ \\
\hline Non-COPD hospitalizations & 10,347 (0.33) & $6,470(0.46)$ & $7,682(0.58)$ & $<0.000 \mathrm{I} /<0.000 \mathrm{I}$ \\
\hline \multicolumn{5}{|l|}{ GP } \\
\hline GP practice in-person visit & $309,543(9.96)$ & $|62,82|(\mid 1.47)$ & $173,822(\mid 3.01)$ & $<0.000 \mathrm{I} /<0.000 \mathrm{I}$ \\
\hline GP practice nurse visit & $106,730(3.43)$ & $58,332(4.11)$ & $67,137(5.02)$ & $<0.000 \mathrm{I} /<0.000 \mathrm{I}$ \\
\hline GP home visit & $5,643(0.18)$ & $3,680(0.25)$ & $4,908(0.36)$ & $0.1763 /<0.0001$ \\
\hline GP out-of-office visit & $2,704(0.08)$ & $2,079(0.14)$ & $2,624(0.19)$ & $<0.000 \mathrm{I} /<0.000 \mathrm{I}$ \\
\hline GP practice administrative contact & $719,613(23.17)$ & $371,698(26.19)$ & $391,748(29.34)$ & $<0.0001 /<0.0001$ \\
\hline GP practice correspondence & $27,843(0.89)$ & I5,764 (I.II) & $16,048(1.20)$ & $<0.000 \mathrm{I} /<0.000 \mathrm{I}$ \\
\hline \multicolumn{5}{|c|}{ Resource category during 12 month observation period, $\mathrm{n}$ (rate) ${ }^{\mathrm{a}}$} \\
\hline Moderate exacerbations & - & $10,952(0.77)$ & $32,302(2.42)$ & NA \\
\hline Severe exacerbations & - & $3,237(0.23)$ & $5,776(0.43)$ & NA \\
\hline Non-COPD hospitalizations & $10,310(0.33)$ & $7,383(0.52)$ & $9,631(0.72)$ & $<0.000 \mathrm{I} /<0.000 \mathrm{I}$ \\
\hline \multicolumn{5}{|l|}{ GP } \\
\hline GP practice in-person visit & $34 I, I 38(10.98)$ & $190,325(13.41)$ & $212,879(15.94)$ & $<0.000 \mathrm{I} /<0.000 \mathrm{I}$ \\
\hline GP practice nurse visit & $128,755(4.14)$ & $80,210(5.65)$ & $96,652(7.23)$ & $<0.000 \mathrm{I} /<0.000 \mathrm{I}$ \\
\hline GP home visit & $6,036(0.19)$ & $5,110(0.36)$ & $7,950(0.59)$ & $0.2986 /<0.0001$ \\
\hline GP out-of-office visit & $2,542(0.08)$ & $2,568(0.18)$ & $4,068(0.30)$ & $<0.000 \mathrm{I} /<0.000 \mathrm{I}$ \\
\hline GP practice administrative contact & $786,50 \mathrm{I}(25.33)$ & $423,124(29.82)$ & $4,57,316(34.25)$ & $<0.000 \mathrm{I} /<0.000 \mathrm{I}$ \\
\hline GP practice correspondence & $22,009(0.70)$ & I3,554 (0.95) & $14,187(1.06)$ & $<0.000 \mathrm{I} /<0.000 \mathrm{I}$ \\
\hline
\end{tabular}

Notes: abserved frequency/total number of patients; "negative binomial regression adjusted for age and sex was used to test any difference in event counts between patients with one and two or more exacerbations events compared with those with no exacerbation event during the 12 month follow-up (referent group). The first $P$-value refers to a comparison of those with one event vs no event; the second $P$-value refers to a comparison of those with two or more events vs those with no events.

Abbreviations: COPD, chronic obstructive pulmonary disease; GP, general practitioner; NA, not applicable for categories where no events in the referent group were recorded. 


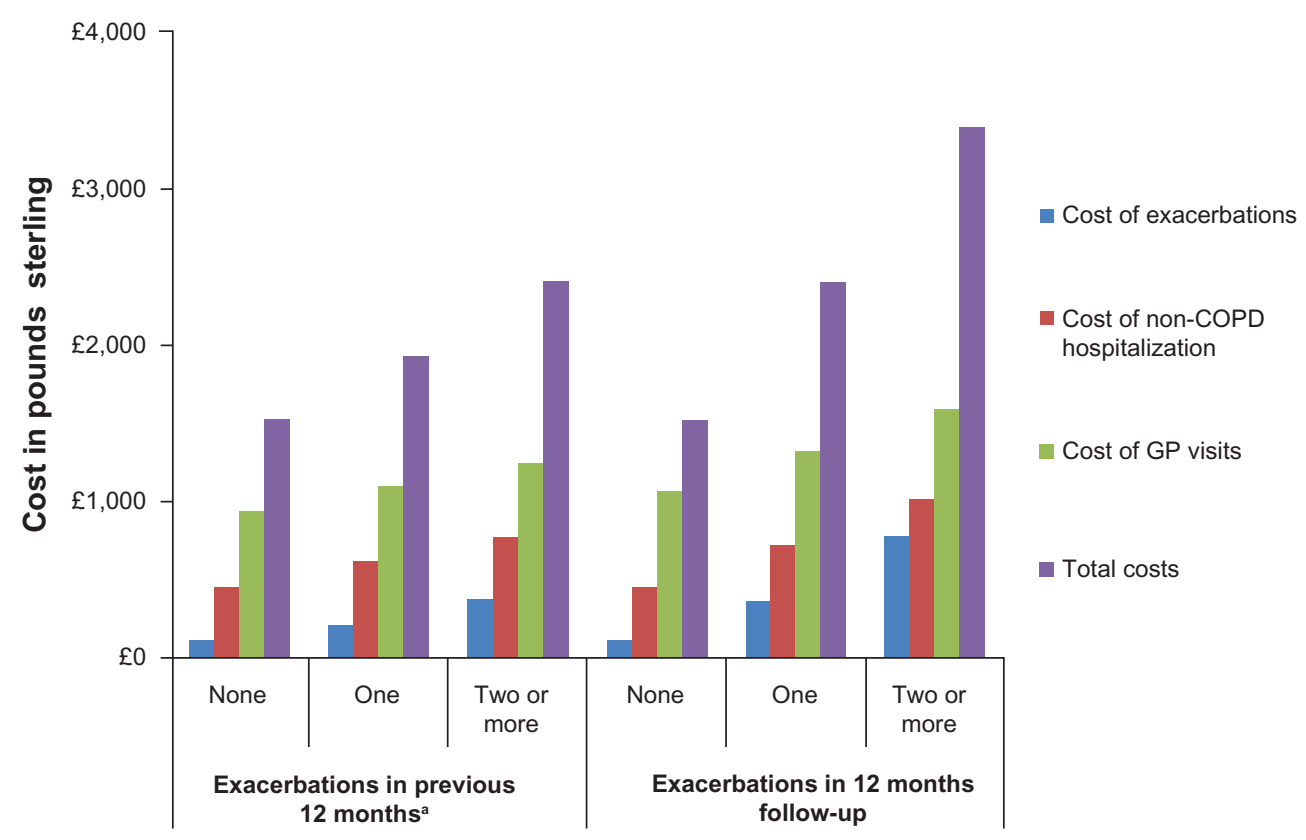

Figure I Costs of COPD treatment (per patient per year) before and after cohort entry date.

Note: ${ }^{\mathrm{C}}$ Classification based on moderate-to-severe exacerbation frequency in the follow-up period.

Abbreviations: COPD, chronic obstructive pulmonary disease; GP, general practitioner.

total annual per patient COPD costs were $£ 1,523, £ 1,928$, and $£ 2,420$, respectively.

The estimated annual COPD management costs (excluding non-exacerbation-related medication costs) during the observation period by GOLD stages of airflow obstruction are presented in Table 4 and by level of dyspnea in Table 5. The mean total annual COPD management costs were $£ 1,767$ for patients with mild dyspnea (MRC grade 1 or 2 ) and $£ 2,534$ for patients with moderate-severe dyspnea.

Similar cost escalations with an increase in dyspnea were also observed in all cost components, including exacerbations ( $£ 182$ versus $£ 342$ ), non-COPD hospitalizations (£504 versus $£ 787$ ), and GP interactions (£1,081 versus $£ 1,404)$. This upward trend in total annual costs and cost

Table 4 COPD management costs split by exacerbation frequency during the observation period and further by GOLD stages of airflow obstruction

\begin{tabular}{|c|c|c|c|c|c|c|}
\hline \multirow{2}{*}{$\begin{array}{l}\text { Exacerbation } \\
\text { frequency }\end{array}$} & \multirow{2}{*}{$\begin{array}{l}\text { GOLD } \\
\text { categories }\end{array}$} & \multirow{2}{*}{$\begin{array}{l}\text { No of } \\
\text { patients }\end{array}$} & \multicolumn{4}{|c|}{ Cost per patient per year } \\
\hline & & & Exacerbations & $\begin{array}{l}\text { Non-COPD } \\
\text { hospitalizations }\end{array}$ & $\begin{array}{l}\text { GP surgery } \\
\text { contact }\end{array}$ & Total \\
\hline \multirow[t]{4}{*}{ All patients } & Stage I & 8,844 & $£ 202.40$ & $£ 621.90$ & $£ I, I 59.76$ & $£ 1,984.06$ \\
\hline & Stage 2 & 29,832 & $£ 232.61$ & $£ 635.89$ & $€ I, 2 \mid 8.50$ & $£ 2,087.00$ \\
\hline & Stage 3 & 15,497 & $£ 319.65$ & $£ 672.90$ & $f 1,297.33$ & $£ 2,289.88$ \\
\hline & Stage 4 & 3,377 & $£ 445.53$ & $£ 775.20$ & $£|, 4| 8.44$ & $£ 2,639.17$ \\
\hline \multirow[t]{4}{*}{ None } & Stage I & 5,475 & $£ 0.00$ & $£ 502.88$ & $E I, 026.4 \mid$ & $E 1,529.29$ \\
\hline & Stage 2 & 16,815 & $£ 0.00$ & $£ 468.84$ & $E I, 068.4 \mid$ & $£ 1,537.25$ \\
\hline & Stage 3 & 7,013 & $£ 0.00$ & $£ 428.50$ & $£ I, 073.42$ & $E I, 501.92$ \\
\hline & Stage 4 & 1,152 & $£ 0.00$ & $£ 405.5 \mathrm{I}$ & $£ \mathrm{I}, 100.32$ & $\in I, 505.83$ \\
\hline \multirow[t]{4}{*}{ One } & Stage I & I,97| & $£ 378.76$ & $£ 731.44$ & $\in I, 286.98$ & $£ 2,397.18$ \\
\hline & Stage 2 & 7,324 & $£ 365.97$ & $£ 738.93$ & $£ \mid, 307.32$ & $£ 2,4 \mid 2.22$ \\
\hline & Stage 3 & 3,855 & $£ 347.98$ & $£ 7 \mid 0.18$ & $£|, 33| .90$ & $£ 2,390.06$ \\
\hline & Stage 4 & 814 & $£ 351.51$ & $£ 682.12$ & $£ \mid, 308.08$ & $£ 2,341.71$ \\
\hline \multirow[t]{4}{*}{ Two or more } & Stage I & I,398 & $£ 753.96$ & $£ 937.95$ & $£ I, 507.45$ & $£ 3,199.36$ \\
\hline & Stage 2 & 5,693 & $£ 754.80$ & $E I, 001.51$ & $\in I, 55 I .82$ & $£ 3,308.13$ \\
\hline & Stage 3 & 4,629 & $£ 789.53$ & $f 1,018.99$ & $E I, 6 \mid 4.04$ & $£ 3,422.57$ \\
\hline & Stage 4 & $|, 4| \mid$ & $£ 871.16$ & $£ 1,137.25$ & $£ \mid, 747.82$ & $£ 3,756.23$ \\
\hline
\end{tabular}

Abbreviations: COPD, chronic obstructive pulmonary disease; GOLD, Global initiative for chronic Obstructive Lung Disease; GP, general practitioner. 
Table 5 COPD management costs split by exacerbation frequency during the observation period and further by levels of dyspnea

\begin{tabular}{|c|c|c|c|c|c|c|}
\hline \multirow{2}{*}{$\begin{array}{l}\text { Exacerbation } \\
\text { frequency }\end{array}$} & \multirow{2}{*}{$\begin{array}{l}\text { MRC dyspnea } \\
\text { scale }\end{array}$} & \multirow[t]{2}{*}{ Patients (n) } & \multicolumn{4}{|c|}{ Cost per patient per year } \\
\hline & & & Exacerbations & $\begin{array}{l}\text { Non-COPD } \\
\text { hospitalizations }\end{array}$ & $\begin{array}{l}\text { GP surgery } \\
\text { contact }\end{array}$ & Total \\
\hline \multirow[t]{5}{*}{ All COPD patients } & MRC I & 9,475 & $£ \mid 47.73$ & $£ 456.67$ & $£ 992.66$ & $E I, 597.06$ \\
\hline & MRC 2 & 19,863 & $£ \mid 98.50$ & $£ 527.08$ & $€ \mathrm{I}, \mid 22.87$ & $€ I, 848.45$ \\
\hline & MRC 3 & $|3,25|$ & $£ 289.63$ & $£ 701.10$ & $£ 1,307.06$ & $£ 2,297.79$ \\
\hline & MRC 4 & 7,440 & $£ 395.54$ & $£ 859.85$ & $£ 1,489.57$ & $£ 2,744.96$ \\
\hline & MRC 5 & 1,612 & $£ 549.09$ & $£ I, 189.76$ & $f 1,840.23$ & $£ 3,579.08$ \\
\hline \multirow[t]{5}{*}{ None } & MRC I & 6,251 & $£ 0.00$ & $£ 367.70$ & $£ 899.43$ & $E I, 267.14$ \\
\hline & MRC 2 & 11,552 & $£ 0.00$ & $£ 4|7.8|$ & $\{1,006.53$ & $£ I, 424.34$ \\
\hline & MRC 3 & 6,478 & $£ 0.00$ & $£ 526.29$ & $€ I, \mid 63.58$ & $€ I, 689.88$ \\
\hline & MRC 4 & 2,959 & $£ 0.00$ & $£ 592.94$ & $€ 1,257.82$ & $£ 1,850.76$ \\
\hline & MRC 5 & 524 & $£ 0.00$ & $£ 763.10$ & $£ 1,472.06$ & $£ 2,235.16$ \\
\hline \multirow[t]{5}{*}{ One } & MRC I & 2,059 & $£ 339.52$ & $£ 560.84$ & $f 1,120.17$ & $£ 2,020.53$ \\
\hline & MRC 2 & 4,765 & $£ 340.54$ & $£ 618.77$ & $£|, 2| 4.69$ & $£ 2,174.00$ \\
\hline & MRC 3 & 3,487 & $£ 368.61$ & $£ 758.89$ & $E 1,334.02$ & $£ 2,461.51$ \\
\hline & MRC 4 & I,876 & $£ 407.57$ & $£ 911.00$ & $€|, 5| 4.72$ & $£ 2,833.29$ \\
\hline & MRC 5 & 398 & $£ 455.75$ & $E I, 202.40$ & $£ \mid, 789.27$ & $£ 3,447.42$ \\
\hline \multirow[t]{5}{*}{ Two or more } & MRC I & 1,165 & $£ 605.03$ & $£ 752.17$ & $f \mid, 269.79$ & $£ 2,477.37$ \\
\hline & MRC 2 & 3,546 & $£ 657.12$ & $£ 761.34$ & $£ \mid, 380.15$ & $£ 2,633.15$ \\
\hline & MRC 3 & 3,286 & $€ 781.61$ & $£ 987.24$ & $£ 1,563.77$ & $£ 3,102.86$ \\
\hline & MRC 4 & 2,605 & $£ 842.87$ & $E 1,130.34$ & $£ 1,738.48$ & $£ 3,487.93$ \\
\hline & MRC 5 & 690 & $£ 1,033.85$ & $f|, 5| 7.05$ & $£ 2,158.54$ & $£ 4,340.16$ \\
\hline
\end{tabular}

Abbreviations: COPD, chronic obstructive pulmonary disease; GP, general practitioner; MRC, Medical Research Council dyspnea scale.

components was observed regardless of exacerbation frequency. This increase in total annual cost between patients with mild and moderate-severe dyspnea was $£ 396$ for patients with no exacerbations, $£ 518$ for patients with one exacerbation, and $£ 862$ for patients with two or more exacerbations in the observation period.

The mean total annual COPD management costs were $£ 2,063$ for mild-moderate patients (GOLD stages 1 and 2) and $£ 2,351$ for severe patients (GOLD stages 3 and 4 ). When split by exacerbation frequency, total costs decreased with increase in severity among patients with no exacerbations $(£ 1,535$ versus $£ 1,502)$ and patients with one exacerbation ( $£ 2,409$ versus $£ 2,382)$. In patients with two or more exacerbations, total costs increased with COPD severity ( $£ 3,287$ versus $£ 3,499$ ). Among the cost components, GP interactions showed an upward trend with increase in COPD severity, regardless of the exacerbation frequency.

A majority of exacerbation costs were associated with severe exacerbations. For the entire cohort, the mean annual per patient cost of moderate and severe exacerbations was $£ 63$ and $£ 194$ in the observation period and $£ 55$ and $£ 145$ in the pre-observation period, respectively. Corresponding costs in the observation period were $£ 67$ and $£ 295$ for patients with one exacerbation and $£ 214$ and $£ 567$ for patients with two or more exacerbations.

\section{Discussion}

This study explored health care resource use and associated costs of COPD patients in the CPRD database. We focused on differences in costs by exacerbation frequency, further split by the GOLD stages of airflow obstruction and the levels of dyspnea. Patients were stratified into three categories of no, one, and two or more moderate-to-severe exacerbations based on an analysis published in the literature. ${ }^{24}$

Our results show that the majority of the health care costs in COPD patients are attributable to GP interactions. In patients with two or more (frequent) exacerbations, these accounted for $47 \%$ of total COPD costs whilst contributing $70 \%$ and $55 \%$ in patients with no and one exacerbation, respectively. A study by McGuire et al assessed the excess cost of chronic bronchitis and acute exacerbations of chronic bronchitis in the UK primary care setting. ${ }^{8}$ They estimated that the excess cost of GP visits attributable to chronic bronchitis and acute exacerbations of chronic bronchitis was $£ 6.5$ million in England and Wales in 1997-1998. Our estimate of $£ 23.3$ million due to in-person GP visits and $£ 61.8$ million due to GP interactions in the CPRD sample alone is significantly higher.

A study reported by Wouters estimated the annual direct cost of COPD patients to be $\$ 1,254$ in the UK in 2002, with mean annual GP visits per person being $6.6 .^{25}$ The estimated cost in our study was $£ 1,826$ in the pre-observation period 
and $£ 2,108$ during the observation period. We estimated the mean annual GP practice visits to be 12.7 among the entire cohort. This suggests a substantial increase in health care use in the primary care setting over the last 10 years. The Wouters study also reported $14 \%$ for patients with hospitalizations and $12 \%$ for emergency room visits. ${ }^{25}$ We found $9.6 \%$ and $21.8 \%$ of patients reporting at least one hospitalization for COPD and non-COPD causes, respectively.

A study by Schermer et al estimated the costs associated with exacerbations in a primary care setting in the Netherlands. Their study reported annual costs of exacerbations as $£ 40, £ 53, £ 61$, and $£ 92$ among patients with no, mild, moderate, and severe airflow obstruction, respectively, in 2001. ${ }^{26}$ The corresponding estimates in our study were $£ 202, £ 233, £ 320$, and $£ 446$, respectively. However, it is important to note that the severity classification used in the study by Schemer et al was based on the European Respiratory Society recommendation, ${ }^{27}$ while ours was based on GOLD. ${ }^{23}$ A study by Andersson et al showed that exacerbations account for $35 \%-45 \%$ of the total per capita health care costs for COPD. ${ }^{28}$ In our study, which was mainly based on the primary care COPD population, exacerbations accounted for less than $25 \%$ of the costs, even for frequent exacerbators, highlighting a relatively small contribution of exacerbation costs to the overall COPD management costs. One possible explanation for the higher proportion of GP costs is the holistic assessment of GP interactions in our study. We included all forms of GP interactions, including non-GP-led interactions within and outside the surgery. Most other studies published in the literature have focused on surgery-based GP-led visits.

In our study, total COPD management costs and its cost components increased with increasing level of disease severity. This was more evident with increasing levels of dyspnea than with increasing levels of airflow obstruction, regardless of the exacerbation frequency. In part, this could be explained by more severe COPD patients having higher comorbidities and thus requiring more GP interactions and non-COPD hospitalization. This hypothesis, however, was not tested in the current study. A similar study by Tabberer et al estimated the incremental annual cost of moderateto-severe dyspnea in general practice to be in excess of $£ 250$ per patient. ${ }^{29}$ Our estimates of the corresponding mean increase in annual COPD management costs with each level increase in dyspnea were $£ 242, £ 357$, and $£ 466$ for patients with no, one, and two or more exacerbations, respectively. Overall, the resource use costs increased with higher levels of exacerbation frequency and dyspnea.
Therefore, efforts to better manage patients in primary care with an aim to reduce exacerbations and symptoms that drive GP visits will help reduce overall COPD management costs significantly.

Our study has several limitations. We excluded the cost of non-exacerbation-related medications from our cost calculations. A previous study has shown medication cost to be a major contributor to overall health care costs. ${ }^{8}$ This may significantly underestimate the annual COPD costs per patient in our analysis. We also used tariff-based cost estimates applicable across England and Wales. Whilst this improves the generalizability of our findings, the actual costs in local settings may differ from national estimates, thereby limiting their applicability to local health economies. Further, patients were included only if their information was available for at least 24 months. Such a condition of a longer stay in a cohort may introduce survival bias, given that patients with a higher disease severity and a higher risk of health care events do not survive for the full follow-up. In addition, the quality of spirometry data is unknown. One study indicated the possibility of a variable quality of spirometry measurement in a primary care population largely not included in the CPRD database. ${ }^{30}$

\section{Conclusion}

Estimated COPD management costs increased with exacerbation frequency and level of dyspnea based on data from 12 months of follow-up in an observational cohort study of patients managed in primary care. Interactions with GP surgery accounted for a substantial proportion of costs regardless of the exacerbation frequency. Further, the costs of GP interactions, exacerbations, and non-COPD hospitalizations increased with increasing levels of dyspnea. Therefore, in a primary care setting, better disease management focused on holistic assessment and reduction of symptoms is required. This is particularly applicable to patients with a low risk of exacerbations, who continue to utilize a significant proportion of health care resources. Future strategies should follow published guidelines such as GOLD to include systematic measurement of symptoms and health status, allowing physicians to identify patients with unmet need and treat them accordingly to improve individual outcomes and the collective burden.

\section{Disclosure}

Editorial support, in the form of development, assembling tables and figures, collating author comments, copyediting, fact checking, and referencing, was performed 
by Dr Annirudha Chillar from Cactus Communications Inc, and was funded by GlaxoSmithKline. The authors have no other conflicts of interest to report.

\section{References}

1. Buist AS, McBurnie MA, Vollmer WM, et al; BOLD Collaborative Research Group. International variation in the prevalence of COPD (the BOLD Study): a population-based prevalence study. Lancet. 2007;370(9589):741-750.

2. Effing T, Kerstjens H, van der Valk P, Zielhuis G, van der Palen J. (Cost)-effectiveness of self-treatment of exacerbations on the severity of exacerbations in patients with COPD: the COPE II study. Thorax. 2009;64(11):956-962.

3. Nurmatov U, Buckingham S, Kendall M, et al. Effectiveness of holistic interventions for people with severe chronic obstructive pulmonary disease: systematic review of controlled clinical trials. PLoS One. 2012;7(10): 46433.

4. Chetty M, MacKenzie M, Douglas G, Currie GP. Immediate and early discharge for patients with exacerbations of chronic obstructive pulmonary disease: is there a role in "real life"? Int J Chron Obstruct Pulmon Dis. 2006;1(4):401-407.

5. Jahnz-Rozyk K, Targowski T, From S. Costs of exacerbations of chronic obstructive pulmonary disease in primary and secondary care in 2007 - results of multicenter Polish study. Pol Merkur Lekarski. 2009;26(153):208-214. Polish.

6. Nielsen R, Johannessen A, Benediktsdottir B, et al. Present and future costs of COPD in Iceland and Norway: results from the BOLD study. Eur Respir J. 2009;34(4):850-857.

7. Ornek T, Tor M, Altin R, et al. Clinical factors affecting the direct cost of patients hospitalized with acute exacerbation of chronic obstructive pulmonary disease. Int J Med Sci. 2012;9(4):285-290.

8. McGuire A, Irwin DE, Fenn P, et al. The excess cost of acute exacerbations of chronic bronchitis in patients aged 45 and older in England and Wales. Value Health. 2001;4(5):370-375.

9. Pasquale MK, Sun SX, Song F, Hartnett HJ, Stemkowski SA. Impact of exacerbations on health care cost and resource utilization in chronic obstructive pulmonary disease patients with chronic bronchitis from a predominantly Medicare population. Int J Chron Obstruct Pulmon Dis. 2012;7:757-764.

10. Dalal AA, Christensen L, Liu F, Riedel AA. Direct costs of chronic obstructive pulmonary disease among managed care patients. Int $J$ Chron Obstruct Pulmon Dis. 2010;5:341-349.

11. Miravitlles M, Murio C, Guerrero T, Gisbert R. Pharmacoeconomic evaluation of acute exacerbations of chronic bronchitis and COPD. Chest. 2002;121(5):1449-1455.

12. Fletcher CM, Elmes PC, Fairbairn AS, Wood CH. The significance of respiratory symptoms and the diagnosis of chronic bronchitis in a working population. BMJ. 1959;2(5147):257-266.

13. Mullerova H, Lu C, Tabberer M. Disease burden of dyspnea in a primary care COPD population. Am J Respir Crit Care Med. 2012; 185:A1518.

14. Clinical Practice Research Datalink. Available from: http://www.cprd. com/home/. Accessed October 4, 2012.

15. Leidy NK, Wilcox TK, Jones PW, Roberts L, Powers JH, Sethi S. Standardizing measurement of chronic obstructive pulmonary disease exacerbations. Reliability and validity of a patient-reported diary. $\mathrm{Am}$ J Respir Crit Care Med. 2011;183(3):323-329.
16. Gov.UK. Policy paper. NHS reference costs 2010-2011. Available from: https://www.gov.uk/government/publications/2010-11-reference-costspublication. Accessed October 4, 2012.

17. Buckingham RJ, Lowe D, Pursey NA, Roberts CM, Stone RA. Report of the National Chronic Obstructive Pulmonary Disease Audit 2008: clinical audit of COPD exacerbations admitted to acute NHS units across the UK: Royal College of Physicians, British Thoracic Scoiety, British Lung Foundation, 2008. Available from: http://www. brit-thoracic.org.uk/Portals/0/Clinical\%20Information/COPD/NCROP/ NCROPClinicalAudit.pdf. Accessed November 17, 2013.

18. Global Initiative for Chronic Obstructive Lung Disease. Global strategy for the diagnosis, management and prevention of COPD (2010). Available from: http://www.goldcopd.org/uploads/users/files/ GOLDReport_April112011.pdf. Accessed November 17, 2012.

19. Personal Social Services Research Unit. Unit Costs of Health and Social Care 2011. Available from: http://www.pssru.ac.uk/project-pages/ unit-costs/2011/index.php. Accessed October 4, 2012.

20. British National Formulary 65, 2012. Available from: http://bnf.org/ bnf/index.htm. Accessed October 4, 2012.

21. Hertel N, Kotchie RW, Samyshkin Y, Radford M, Humphreys S, Jameson K. Cost-effectiveness of available treatment options for patients suffering from severe COPD in the UK: a fully incremental analysis. Int J Chron Obstruct Pulmon Dis. 2012;7:183-199.

22. Global Initiative for Chronic Obstructive Lung Disease. Global strategy for the diagnosis, management, and prevention of chronic obstructive pulmonary disease (2006). Available from: http://www. goldcopd.org/uploads/users/files/GOLDReport2006_0122.pdf. Accessed October 4, 2012

23. National Institute for Health and Care Excellence. Medical Research Council dyspnea scale. Available from: http://www.nice.org.uk/ usingguidance/commissioningguides/pulmonaryrehabilitationservicefor patientswithcopd/mrc_dyspnoea_scale.jsp. Accessed June 20, 2011.

24. Hurst JR, Vestbo J, Anzueto A, et al. Susceptibility to exacerbation in chronic obstructive pulmonary disease. $N$ Engl J Med. 2010;363(12): $1128-1138$.

25. Wouters EF. Economic analysis of the Confronting COPD survey: an overview of results. Respir Med. 2003;97 Suppl C:S3-S14.

26. Schermer TR, Saris CG, van den Bosch WJ, et al. Exacerbations and associated health care cost in patients with COPD in general practice. Monaldi Arch Chest Dis. 2006;65(3):133-140.

27. Siafakas NM, Vermeire P, Pride NB, et al. Optimal assessment and management of chronic obstructive pulmonary disease (COPD). The European Respiratory Society Task Force. Eur Respir J. 1995;8(8): $1398-1420$.

28. Andersson F, Borg S, Jansson SA, et al. The costs of exacerbations in chronic obstructive pulmonary disease (COPD). Respir Med. 2002;96(9):700-708.

29. Tabberer M, Lu C, Müllerova H. Incremental burden of dyspnea in COPD to a primary care COPD population. Presented at the Annual Congress of the American Thoracic Society, San Francisco, CA, USA, May 18-23, 2012.

30. Strong M, South G, Carlisle R. The UK Quality and Outcomes Framework pay-for-performance scheme and spirometry: rewarding quality or just quantity? A cross-sectional study in Rotherham, UK. BMC Health Serv Res. 2009;9:108. 


\section{Supplementary materials}

Table SI COPD management costs according to the frequency of COPD exacerbations in UK primary care

\begin{tabular}{|c|c|}
\hline ReadCode description & ReadCode \\
\hline \multicolumn{2}{|c|}{ COPD ReadCodes used to extract the study COPD cohort } \\
\hline \multicolumn{2}{|l|}{ from the electronic medical records } \\
\hline Acute exacerbation of COAD & $\mathrm{H} 312200$ \\
\hline Admitted COPD emergency & $8 \mathrm{H} 2 \mathrm{R} .00$ \\
\hline Airways obstruction irreversible & $663 \mathrm{~K} .00$ \\
\hline Chronic bronchitis with emphysema & $49 I \mathrm{E}$ \\
\hline COAD follow-up & 66YL.12 \\
\hline COPD & $5199 \mathrm{GP}$ \\
\hline COPD follow-up & 66YL.II \\
\hline COPD self-management plan given & $66 \mathrm{YI} .00$ \\
\hline Centrilobular emphysema & $\mathrm{H} 322.00$ \\
\hline COPD with acute exacerbation, unspecified & H3yl.00 \\
\hline Chronic bullous emphysema & $\mathrm{H} 320.00$ \\
\hline Chronic bullous emphysema NOS & $\mathrm{H} 320 \mathrm{z} 00$ \\
\hline COPD with acute lower respiratory infection & H3y0.00 \\
\hline COAD & $\mathrm{H} 3 \ldots \mathrm{II}$ \\
\hline COAD NOS & H3z..00 \\
\hline COPD & $\mathrm{H} 3 \ldots . .00$ \\
\hline COPD NOS & H3z..II \\
\hline COPD annual review & 66YM.00 \\
\hline COPD clinical management plan & $8 C R I .00$ \\
\hline COPD disturbs sleep & $66 Y g .00$ \\
\hline COPD does not disturb sleep & 66Yh.00 \\
\hline COPD follow-up & 66YL.00 \\
\hline COPD monitor phone invite & $90 i 4.00$ \\
\hline COPD monitoring & 66 YB. 00 \\
\hline COPD monitoring Ist letter & $90 i 0.00$ \\
\hline COPD monitoring 2 nd letter & $90 i 1.00$ \\
\hline COPD monitoring 3 rd letter & $90 \mathrm{i} 2.00$ \\
\hline COPD monitoring administration & $90 \mathrm{Oi..00}$ \\
\hline COPD monitoring by doctor & 66YT.00 \\
\hline COPD monitoring by nurse & 66YS.00 \\
\hline COPD monitoring due & 66YD.00 \\
\hline COPD monitoring verb invite & $90 i 3.00$ \\
\hline Emphysema pulmonary & 492 \\
\hline Exacerbation COAD & 5199GE \\
\hline Emphysema & $\mathrm{H} 32 . .00$ \\
\hline Emphysema NOS & $\mathrm{H} 32 \mathrm{z} .00$ \\
\hline Emphysematous bronchitis & $\mathrm{H} 312100$ \\
\hline Health education - COPD & $679 V .00$ \\
\hline Mild COPD & $\mathrm{H} 36 . .00$ \\
\hline Moderate COPD & $\mathrm{H} 37 . .00$ \\
\hline COAD & $5199 \mathrm{G}$ \\
\hline
\end{tabular}

(Continued)
Table SI (Continued)

Obstructive chronic bronchitis NOS

$\mathrm{H} 3 \mathrm{I} 2 \mathrm{z} 00$

Radiological emphysema

9906E

Severe COPD

$\mathrm{H} 38 . .00$

Very severe COPD

$\mathrm{H} 39 . .00$

Abbreviations: COPD, chronic obstructive pulmonary disease; COAD, chronic obstructive airways disease; NOS, not otherwise specified.

Number of patients with a recorded diagnosis of COPD on/after April 1, 2009 to June 30, 2011: 107,504

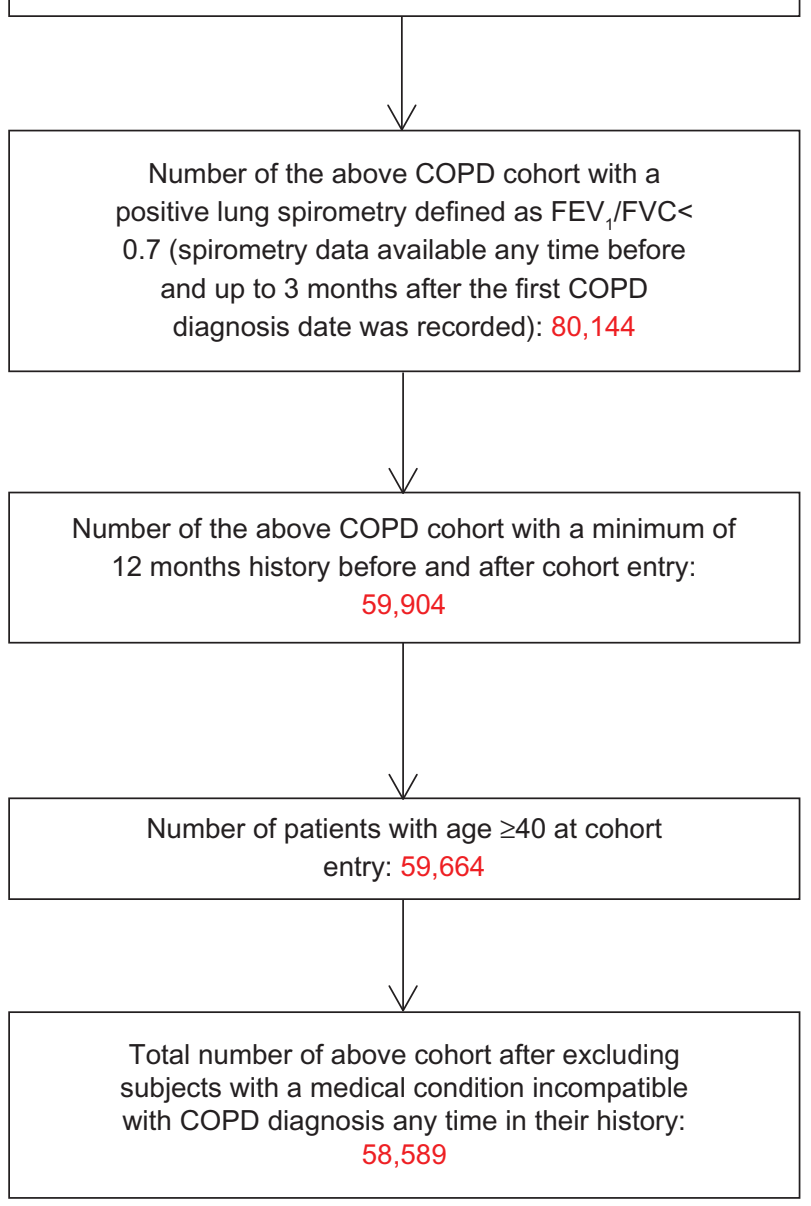

Figure SI Study flow chart.

Abbreviations: COPD, chronic obstructive pulmonary disease; $\mathrm{FEV}_{1}$, forced expiratory volume at one second; FVC, forced vital capacity.

International Journal of COPD

\section{Publish your work in this journal}

The International Journal of COPD is an international, peer-reviewed journal of therapeutics and pharmacology focusing on concise rapid reporting of clinical studies and reviews in COPD. Special focus is given to the pathophysiological processes underlying the disease, intervention programs, patient focused education, and self management protocols.

This journal is indexed on PubMed Central, MedLine and CAS. The manuscript management system is completely online and includes a very quick and fair peer-review system, which is all easy to use. Visit http://www.dovepress.com/testimonials.php to read real quotes from published authors. 